\title{
An Agile Standardized Work Procedure for Cleaning the Operating Room
}

\author{
David Claudio ${ }^{1}$ (D), Virginia Cosgriff² (iD), Valentina Nino $^{2}(\mathbb{D})$, Leonardo Valladares ${ }^{2}$ (D) \\ ${ }^{1}$ University of Massachusetts- Lowell (United States) \\ ${ }^{2}$ Montana State University (United States) \\ David_Claudio@uml.edu,virginia.cosgriff@mcgough.com,valentinanino@gmail.com,leovalla@gmail.com
}

Received: December 2020

Accepted: July 2021

\section{Abstract:}

Purpose: This research aimed to reduce the turnover time (non-operative time) in the operating room (OR) at a US Northwestern hospital.

Design/methodology/approach: Data collection consisted of observation and interviews of the aides, circulating nurses, and surgical techs to identify causes of delays and long turnovers. It was determined that the turnover could be divided into two stages: cleaning the room and setting up for the next surgery. The research team met with the staff (aides) to create a standard operating procedure for the cleaning stage. It was decided to create an agile standard procedure that would allow the process to be completed the same way effectively with any number of people ranging from 1 to 3 . The flexibility accounts for the number of people who are to complete the procedure and considers that some of them are only available during portions of the cleaning stage due to multiple turnovers or duties.

Findings: The agile cleaning procedure reduced the cleaning time by 2.2 minutes (15.7\% of the total time) and the standard deviation by 3.30 minutes. A decrease in variability represents more consistent turnovers, creating more predictable times for scheduling surgeries in the future.

Originality/value: This research proposes a novel approach to standardized work that quickly adapts to the number of workers available. The agile standardized work procedure (ASWP) allows the process to be completed the same way every time effectively with any number of people.

Keywords: operating room, agile standardized work procedure, agile, lean healthcare, turnover

\section{To cite this article:}

Claudio, D., Cosgriff, V., Nino, V., \& Valladares, L. (2021). An Agile Standardized Work Procedure for Cleaning the Operating Room. Journal of Industrial Engineering and Management, 14(4), 701-717. https://doi.org/10.3926/jiem.3440

\section{Introduction}

Operating Rooms (ORs) generate the largest revenue and losses in a hospital (Cima, Brown, Hebl, Moore, Rogers, Kollengode et al., 2011; Fogliatto, Anzanello, Tonetto, Schneider \& Muller Magalhães, 2020; Koyle, AlQarni, Odeh, Butt, Alkahtani, Konstant et al., 2018). Without the prompt cleaning and set-up of the operating suites, the OR would not be able to start surgeries on-time or conduct as many surgeries in its busy schedule. One aspect of OR 
cost, which does not create revenue is the turnover or turnaround time. Turnover time is the time interval from when the patient exits the room until the next patient enters the room (Worley \& Doolen, 2011). It includes the time it takes for cleaning and preparing a room for the next surgery.

According to our partner hospital's data, the cost of running an OR is approximately $\$ 33$ per minute. When a patient is in the room, the hospital charges the patient or insurance, making up the operating costs. However, the time between surgeries is an opportunity cost translated into money not earned by the hospital. Therefore, the goal is to minimize the average time and the standard deviation for turnovers. Decreasing the turnovers could decrease time and cost and increase OR availability for additional surgeries. Simultaneously, a decrease in standard deviation is a good indicator of precision within a process. On the other hand, processes with a lack of stability are almost impossible to improve because they behave differently every day. Therefore, any representation of the process will not match the real condition (Dal Forno, Pereira, Forcellini \& Kipper, 2014). Consequently, creating predictable turnovers could increase patient and staff satisfaction if everything is running on time. One way to achieve precision in processes is through the use of standardized work procedures.

Standardized work can be defined in many ways; Krichbaum (2008) defines it as "a detailed and documented system in which production workers both develop and follow a repeatable sequence of tasks within a work assignment." The standardized work sequence represents the best-known way to complete a task for the operator to follow in the completion of his/her job. Standardization is important as it serves to maintain order and consistency in operations (Freivalds, 2009). Fireman, Saurin and Formoso (2018) added that standardized work aims to reduce process variation and set the baseline for continuous improvement. Graban (2012) describes standardized work as "the current best way to safely complete an activity with the proper outcome and the highest quality, using the fewest possible resources."

Many researchers have reported the benefits of standardized work in healthcare operations (Bakken, Cimino \& Hripcsak, 2004; Lehmann \& Miller, 2004; Pérez \& Porres, 2010; Simpson, 2009). However, Akmal, Greatbanks and Foote (2020) recently found that while many researchers have applied different Lean tools and techniques in healthcare, only $4 \%$ out of 299 articles mentioned some sort of standardization. Their findings indicate that standardized work has not been documented well in healthcare, let alone in ORs. Some researchers have argued that healthcare should create and implement more standardized procedures (Lehmann \& Miller, 2004).

Other benefits of standardized work include the documentation of current processes, variability reduction, training of new operators, and a baseline for improvements (Marchwinski \& Shook, 2008). Lehmann and Miller (2004) state that "standardization reduces variation in clinical treatment and patient outcome and thus improves the quality of patient care, making it safer as well by reduction of potential errors." For this research, standardized work refers to finding the optimal way to complete a task or activity each time the activity is performed. Similarly, standardization is defined in this work as the process to develop standardized work.

The turnover process consists of two parts: cleaning the room and preparing it for the next surgery. This research focused on creating standardized work procedures for the cleaning portion of OR turnovers. Figure 1 presents a swim lane chart of all activities and entities involved in turning a room at the partner hospital. The times presented are averages from historical data and direct observations. The entire turnover process is encapsulated in the red dotted line while the cleaning portion is circled in a yellow line.)

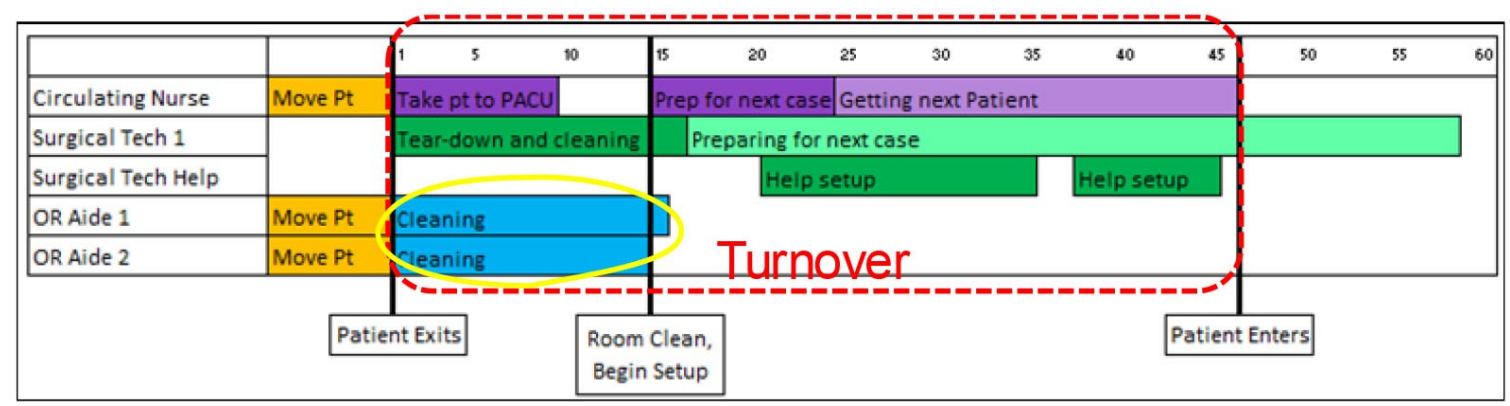

Figure 1. Staff interactions during a turnover 
One difficulty presented in this study was the fact that OR aides, who were the people in charge of cleaning the suites, would come in and out of a room at different times. For example, three people were cleaning a room in some instances, and two would leave because another room needed cleaning. In other instances, only one person was cleaning, and a second would come in to help. Sometimes a third would join a few minutes later. This variability in the number of people at any point in time made it difficult to establish a standardized work procedure in its traditional fashion. For this reason, we decided to create a standardized work procedure that could be flexible enough to account for an unspecified number of staff members in the room.

We proposed a novel approach to standardized work that quickly and easily adapts to the number of workers available. The agile standardized work procedure (ASWP), which focused on the cleaning portion of turnovers, allows the process to be completed the same way every time effectively with any number of people. Furthermore, the number of people cleaning a room can change during the process and still accomplish the same tasks, making this a novel way to look at operations.

A comprehensive literature review using a strategy similar to the one presented by Vest, Gamm, Oxford, Gonzalez and Slawson (2010) was conducted to search for articles proposing anything similar to agile standardized work. The literature search, as seen in Figure 2, consisted of eleven keywords and four databases: Cinahl, Web of Science, Inspec, and Compendex. The keywords included terms such as agile standardized work, flexible standard work, dynamic standardized work, varying number of people for a standard procedure, standardized work varying people, among others.

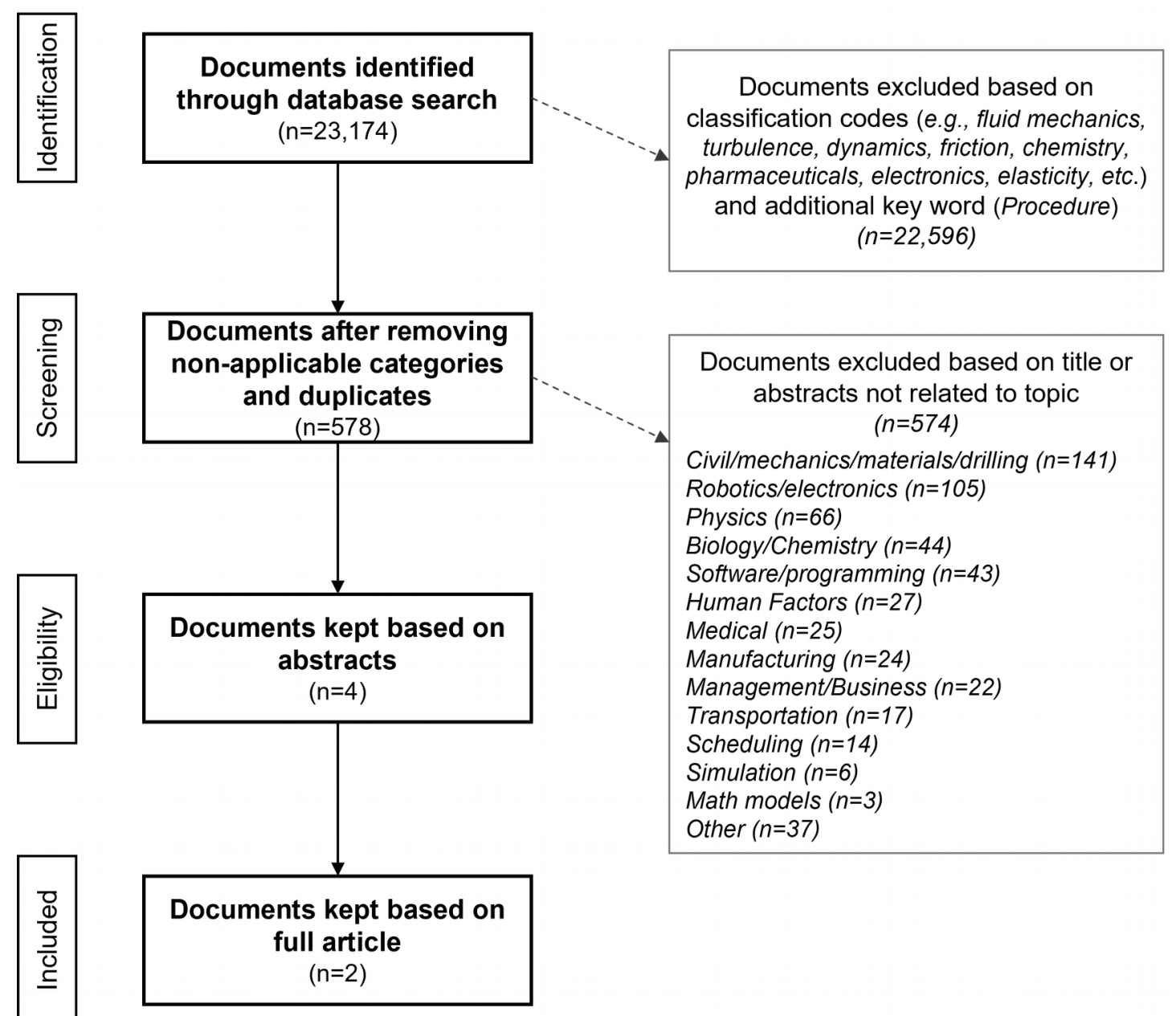

Figure 2. Agile Standardized Work Literature Search 
The initial search results were reduced by only English documents, using classification codes, vocabulary, and additional keywords: procedure and healthcare. Two articles, one by de Mast, Kemper, Does, Mandjes and van der Bijl (2011) and another by Reichert, Dadam and Bauer (2004), were the closest to this type of procedure in the search performed. Both articles are simulation articles that allow for flexibility in resources and scheduling. However, de Mast et al. (2011) simulated patient flows and gave an example of the computerized tomography (CT) scan process. The simulations allow for flexibility, but not as a standardized work procedure, such as the one created in this research.

Poth and Wolf (2017) talked about agile procedures, although they focus their work on the field of Agile Software Development. Recently, Agile methods have been extensively used in a wide variety of projects in many organizations since they allow organizations to be more responsive to changes and deliver products in faster, better, and cheaper ways (Carroll, Bjørnson, Dingsøyr, Rolland \& Conboy, 2020; Chkouri, 2019; de Oliveira Rosa \& Goldman, 2020; Dingsøyr, Dybå, Gjertsen, Jacobsen, Mathisen, Nordfjord et al., 2019; Iivari \& Iivari, 2011; Jabar, Ali, Jusoh, Abdullah \& Mohanarajah, 2019; Sommer, 2019). The agile way of working has been focused on accelerating digital products with some applications in product manufacturing (Kumar, Singh \& Jain Sanjiv, 2019a, 2019b; Lokhande \& Sarode, 2020). However, it has not explored the generation of standardized procedures that contemplated variation on the execution based on resources' temporal availability. To the best of the authors' knowledge, this is the first type of study that proposes an agile or flexible standard work procedure.

\section{Materials and Methods}

The research study was performed at the OR of a medium-size hospital. The hospital is a medium volume Acute Care facility, with 86 beds and over 2,000 employees, of which 200 are physicians. The health professionals cover over 35 specialties and compose more than 20 clinics. It has seven surgical suites ( 6 surgery +1 procedure room), Labor and Delivery department, Emergency Department, Diagnostic \& Treatment areas, and associated on-site clinical programs. The operating rooms work five days a week from $6: 30$ am to $4 \mathrm{pm}$ according to daily surgical schedules and have staff and doctors on call 24-7.

There were five OR aides, and two pairs work together most often due to the times that they were scheduled to work. The aides worked a staggered schedule working for an 8-hour shift starting at 6:30 am, $8 \mathrm{am}, 10 \mathrm{am}, 12 \mathrm{noon}$, and $2 \mathrm{pm}$.

One type of surgery was chosen to collect accurate data for the research study. The type of surgery needed to occur often enough that it was easy to collect data. This would allow more standard observations when taking data and the opportunity to test the procedures. Orthopedic cases with total knee or hip arthroplasty (also known as totals or replacements) and revisions were chosen due to the number of instruments in use and the frequency of occurrence. These surgeries occurred at least ten times a week by five surgeons who performed these procedures, two of which performed total knee and hip procedures exclusively. Observations and analysis of the current tasks occurred during the first two months of the study. Times were taken during months three and four.

According to Freivalds (2009), if the cycle time for a process is between 10-20 minutes, the recommended number of cycles for data collection is eight. Given that the length of time of the cleaning portion of the turnovers ranged from around 13.55 minutes to 25 minutes, it was decided to do 12 timed observations.

Four of the five OR aides were observed cleaning and performing OR aide duties during the turnovers. The number of people in the room ranged from 1-4 depending on availability for the turnover because multiple turnovers can occur simultaneously.

Spaghetti diagrams were drawn for the aides. A spaghetti diagram (SD) is a technique used to observe an object or person's movement within a system. It is a visual representation that uses a continuous flow line tracing the person's path or object through a process. This tool allows the process team to identify opportunities to expedite process flow and redundancies in the workflow (Gladysz, Santarek \& Lysiak, 2017; Senderska, Mares \& Vaclav, 2017). The processes SDs did not show as much waste. However, it did show the interaction and confusion of having too many people helping. 
We also used the Critical Path Method (CPM) to find out the shortest possible time according to times taken from the observations and precedence of different activities. CPM is a project management technique that is widely used in construction projects. It breaks the project into work tasks and defines logical relationships between them. The tasks are presented in a diagram, and the project duration is calculated based on each task duration. This method defines the tasks that are critical to complete the project and identifies the longest path (the critical path) (Olivieri, Seppänen, Alves, Scala, Schiavone, Liu et al., 2019; Zareei, 2018). Prior to CPM, the prediction was that the cleaning time is best done by two people and cannot be faster than 12 minutes.

In collaboration with the aides, the researchers created an agile way of cleaning, which accounted for the variability in the number of people cleaning the room. The ASWP would ideally make the time 12 minutes with two people. Each of the two people starts with specific tasks, the first done from their tasks grabs the mop, while the other will start prepping the room once they are done with their tasks. Whoever is done from the second round of tasks will take care of resetting or changing the Neptune and putting kick bucket bags. Before leaving the room, at least one of them should do the final check, if not both.

Two versions of the same ASWP were created: a detailed ASWP and a concise ASWP. The detailed ASWP consisted of many pictures and a descriptive narrative of tasks in the procedure, whereas the concise ASWP contained minimal pictures and as few words/phrases as needed. An experiment to compare both ASWP was performed to determine which one was more appropriate. Metrics of interest were the cleaning completion time and adherence to the ASWP.

\section{Results}

\subsection{Current State}

The cleaning process starts when a turnover is called (overhead or by a paging system) and ends when the last person cleaning leaves the room, as shown in figure 1. The researchers timed past the point when the last aide or helper left the room because sometimes, they were called back in to get something from the store or supply room. A Current State Value Stream Map (VSM) (Rother \& Shook, 1999) was developed for the OR cleaning procedure (Figure 3). VSM is one of the most valuable tools to understand the current process status better and recognize opportunities for improvements (Dal Forno et al., 2014).

From the Current State VSM, it can be seen that a few activities need prior activities to be completed before they can begin (precedence). It also shows that there are quite a few activities that can happen in parallel.

According to the Association of Registered OR Nurses (AORN, 2012), the precedence of tasks in cleaning an OR are:

1. Nothing can be cleaned until the patient leaves the room.

2. Everything must be cleared from the bed and tables before cleaning with vindicator

3. A top-down approach must be used so that if contamination falls down, the objects below have not been sterilized yet, thus not contaminating anything else. Therefore, the lights must be cleaned before the bed and the bed and tables must be cleaned before mopping.

4. The new circuit cannot be put onto the anesthesia machine until the room is sterile.

5. Linens cannot be put onto the bed until the room is sterile to eliminate a chance of contamination.

6. Sterile supplies cannot be opened until the linens have stopped moving in case particles are in the air and contaminate the sterile field/supplies.

7. The contents of the Neptune and kick-bucket bags do not hold-up the turnover as mopping does, so they are saved for last while other activities (such as opening supplies) are happening. However, the Neptune and kick-buckets will need to be wiped off contamination during the first stage of wiping everything with vindicator. 
Given the instructions recommended by the AORN and the tasks delineated by the VSM, a precedence diagram was created and analyzed using the Critical Path Method (CPM). Figure 4 presents the CPM for cleaning. The CPM shows three paths according to the fastest, average, and slowest times- each depicted by a different color. This method showed that the fastest a room could be cleaned, on average, was 12.2 minutes. The number of paths in the CPM showed that the maximum number of people cleaning a room should not exceed three at any point in time.

A modified version of the critical path for cleaning, seen in Figure 5, assumes that nothing can start until all the trash and linens are removed from the items needing to be cleaned. According to the possible paths that can be taken, the CPM shows that if four people were cleaning, there would not be enough for the fourth person to do according to tasks' precedence.

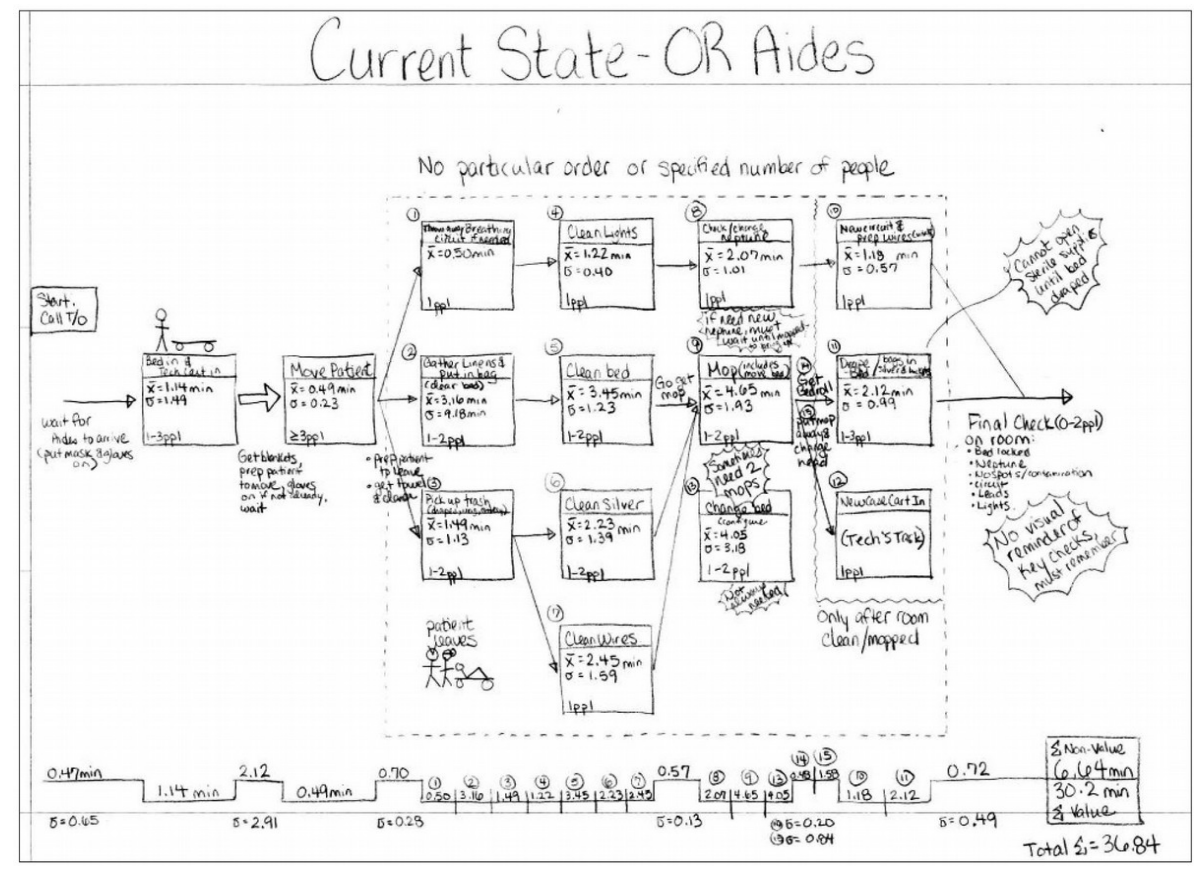

Figure 3. OR Aide Current State Value Stream Map

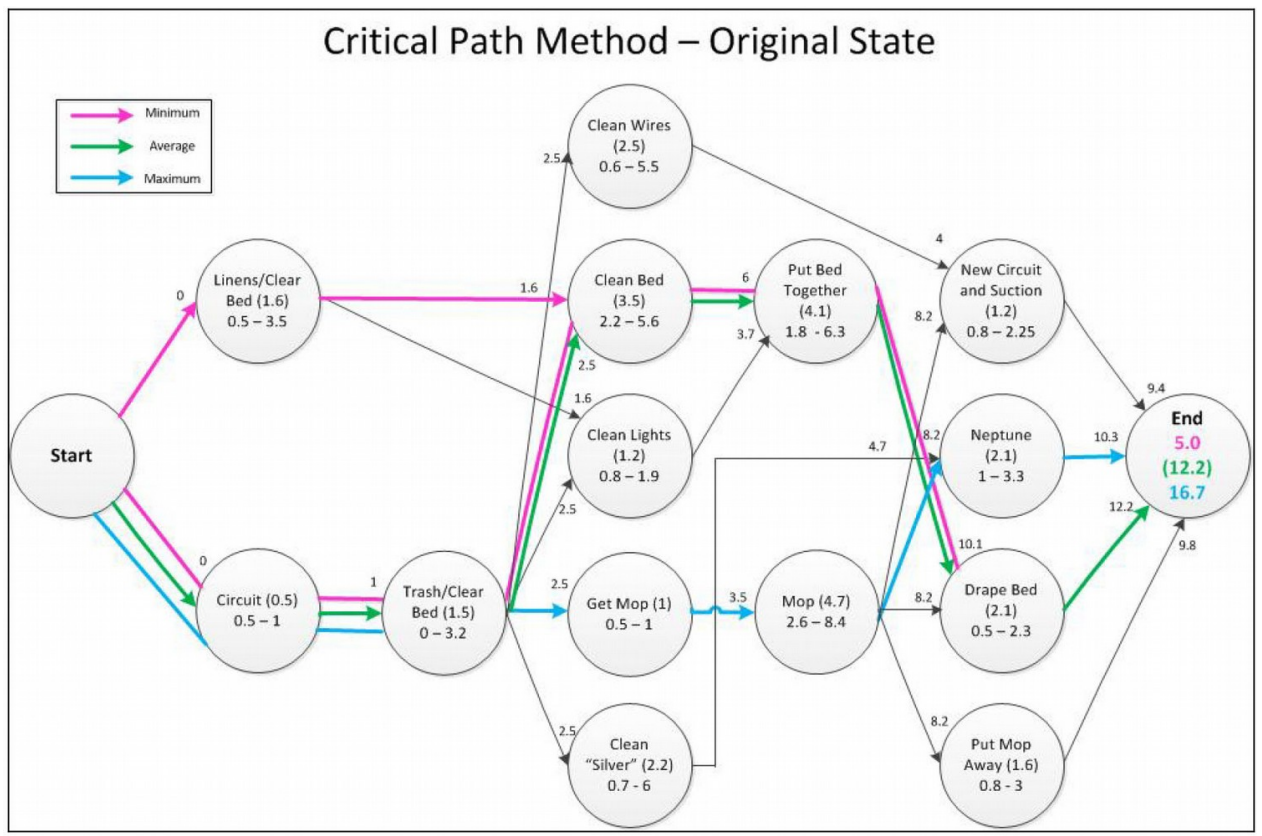

Figure 4. CPM for the original cleaning method 


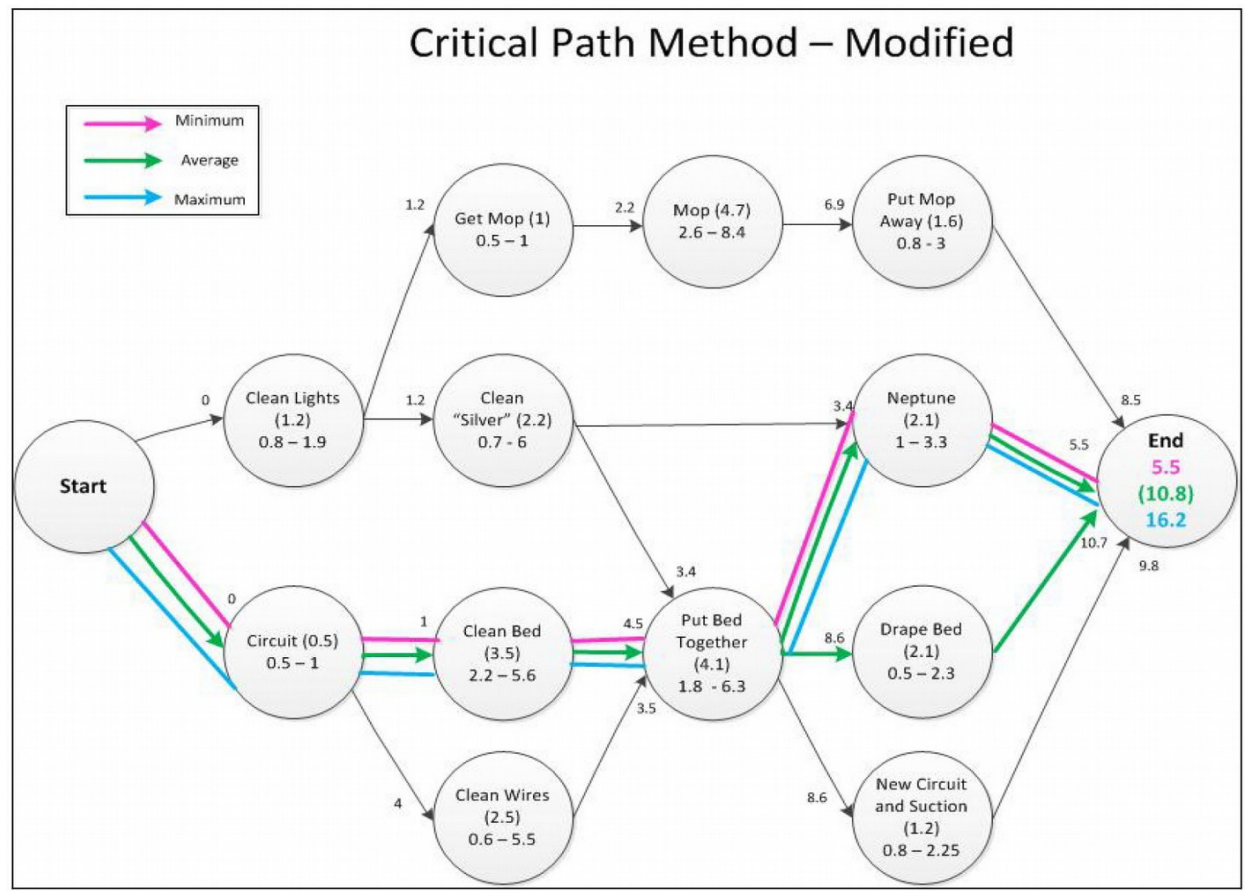

Figure 5. CPM modified with trash and linens assumption

\subsection{Root Cause Analysis}

A root cause analysis was performed with the OR aides, nurses, and staff. Figure 6 presents a fishbone diagram (Ishikawa \& Loftus, 1990) created to identify reasons for the lengthy turnover times. From the figure, it can be seen that there were a lot of opportunities for improvement. Nevertheless, we decided to focus on the process category as many of the causes were triggered primarily by lack of standardization and lack of communication. We circled with a red dotted line the causes or reasons we wanted to tackle by creating a Standardized Work Procedure. As previously mentioned, the task at hand was not simplistic since the number of aides available to clean a room could change even after the cleaning process had started.

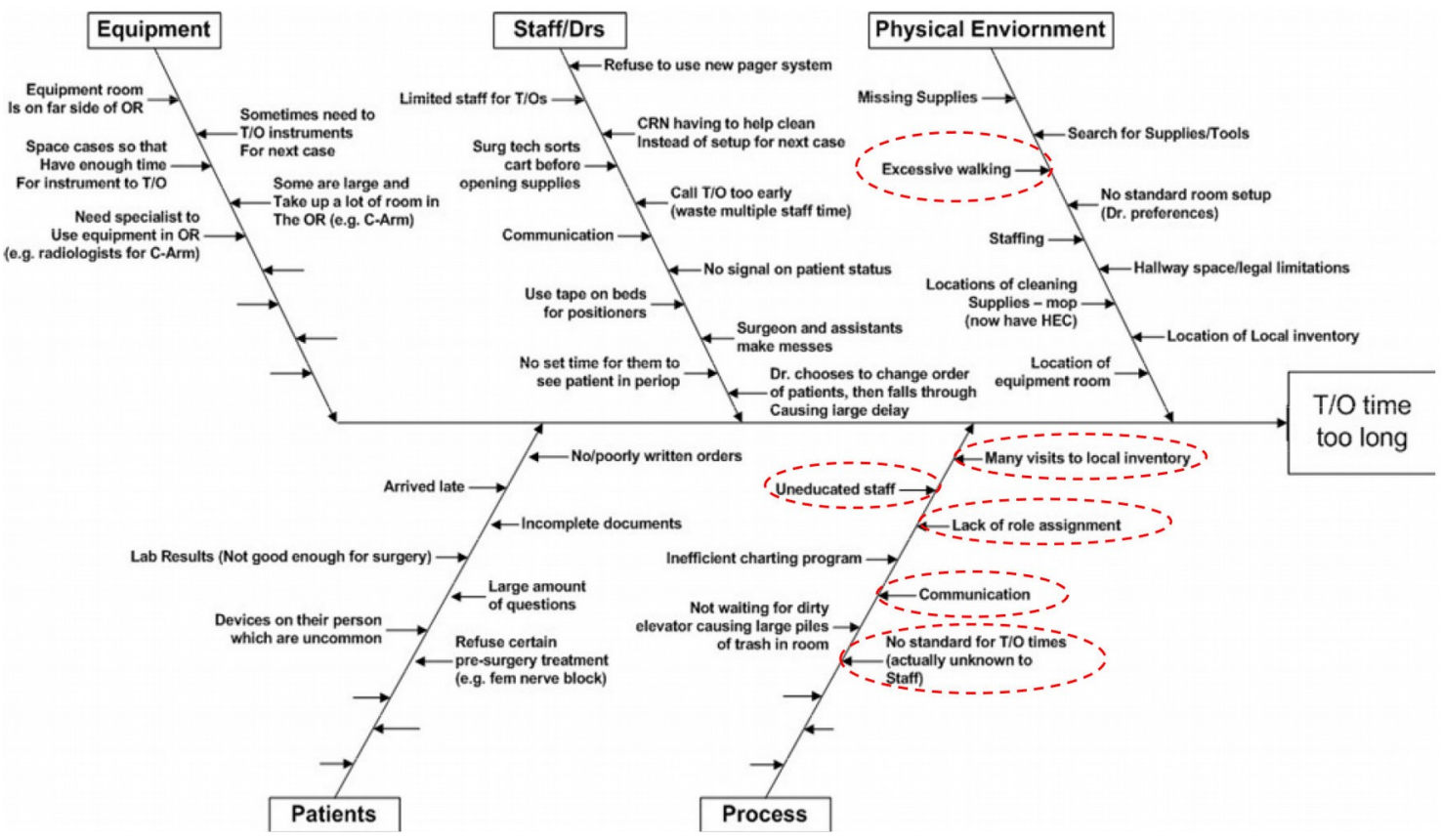

Figure 6. Fishbone diagram of the OR turnover process 


\subsection{Countermeasure: Agile Standardized Work Procedure for Cleaning the Operating Room}

A team of OR aides and the research team agreed that a standardized work procedure would allow cleaning the rooms the same way every time. This would help with the lack of communication, lack of role assignment, lack of standards, and could be used as a training tool for new aides. Besides, by knowing exactly what is needed and when it is needed, the aides would reduce the number of visits to the local inventory, reducing excessive walking. However, the standardized work procedure needed to quickly and easily adapt to the number of aides available at any point in time.

We organized a Kaizen Event (Gonzalez-Aleu, Van Aken-Eileen, Cross \& Glover-Wiljeana, 2018; Marin-Garcia, Juarez-Tarraga \& Santandreu-Mascarell, 2018) in collaboration with the aides where we created an agile way of cleaning which accounted for the unpredictable number of people available. Using the Current State VSM and the CPM diagram, the proposed ASWP was developed by clustering tasks that had precedence (serial tasks) in groups and creating parallel streams of those groups (parallel tasks) while preserving the required precedence between and within groups. Figure $7 \mathrm{a}$ presents the Kaizen Event intended to create the ASWP. Figure 7b presents the first iteration in which tasks were allocated to different groups while preserving the required precedence. Figure $7 \mathrm{c}$ presents the final iteration, which resulted in a more efficient grouping of tasks. Two aides led this last iteration.

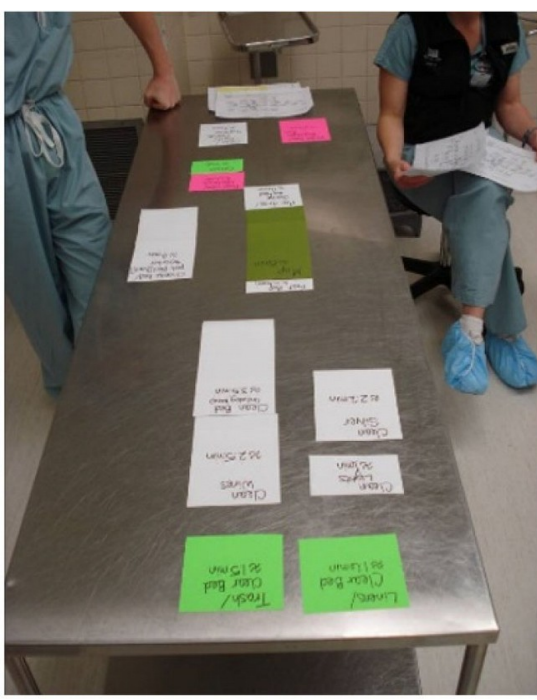

(a)

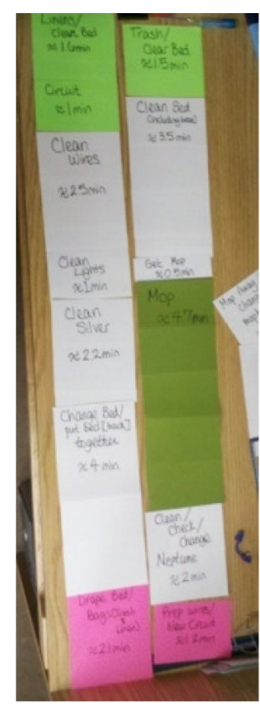

(b)

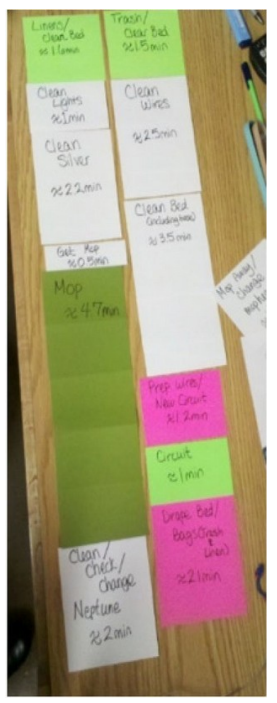

(c)

Figure 7. a) Kaizen team working on redistribution of tasks for ASWP; b) First iteration; c) Second and final iteration

The proposed ASWP would ideally reduce the cleaning time under 12 minutes with two people. Each person starts with specific tasks, the first done from their tasks grabs the mop, while the other starts prepping the room once they are done with their tasks. Whoever is done first with the second round of tasks takes care of resetting or changing the Neptune and putting kick bucket bags. Before leaving the room, at least one of them performs a final check, if not both.

After the Kaizen team created the ASWP, we came up with a visual representation so that everyone could read it. Two versions of the ASWP were created, one with many pictures and a descriptive narrative of tasks in the procedure (detailed), and one with minimal pictures and few words/phrases as needed (concise). We used visual management tools such as color-coding, numbers, and a visual algorithm to denote what needs to take place next.

Figures 8 and 9 present the detailed and concise ASWP, respectively. The pictures for the procedures were taken during actual turnovers. Permission was given by the OR manager and staff as long as they did not show any patient identifiers. The two procedures were designed for 11"x17" paper to allow details to be viewed. 


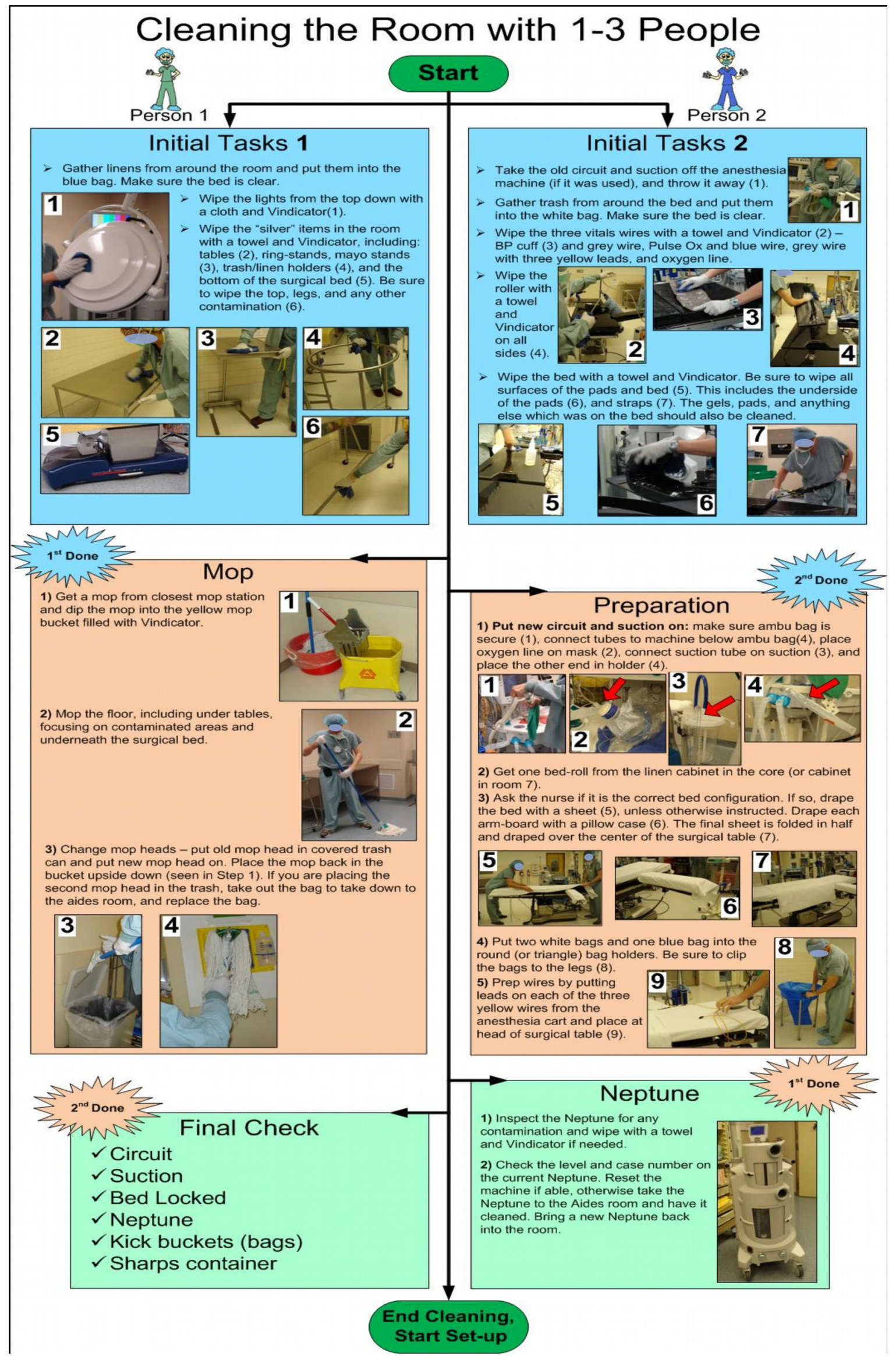

Figure 8. Detailed ASWP 


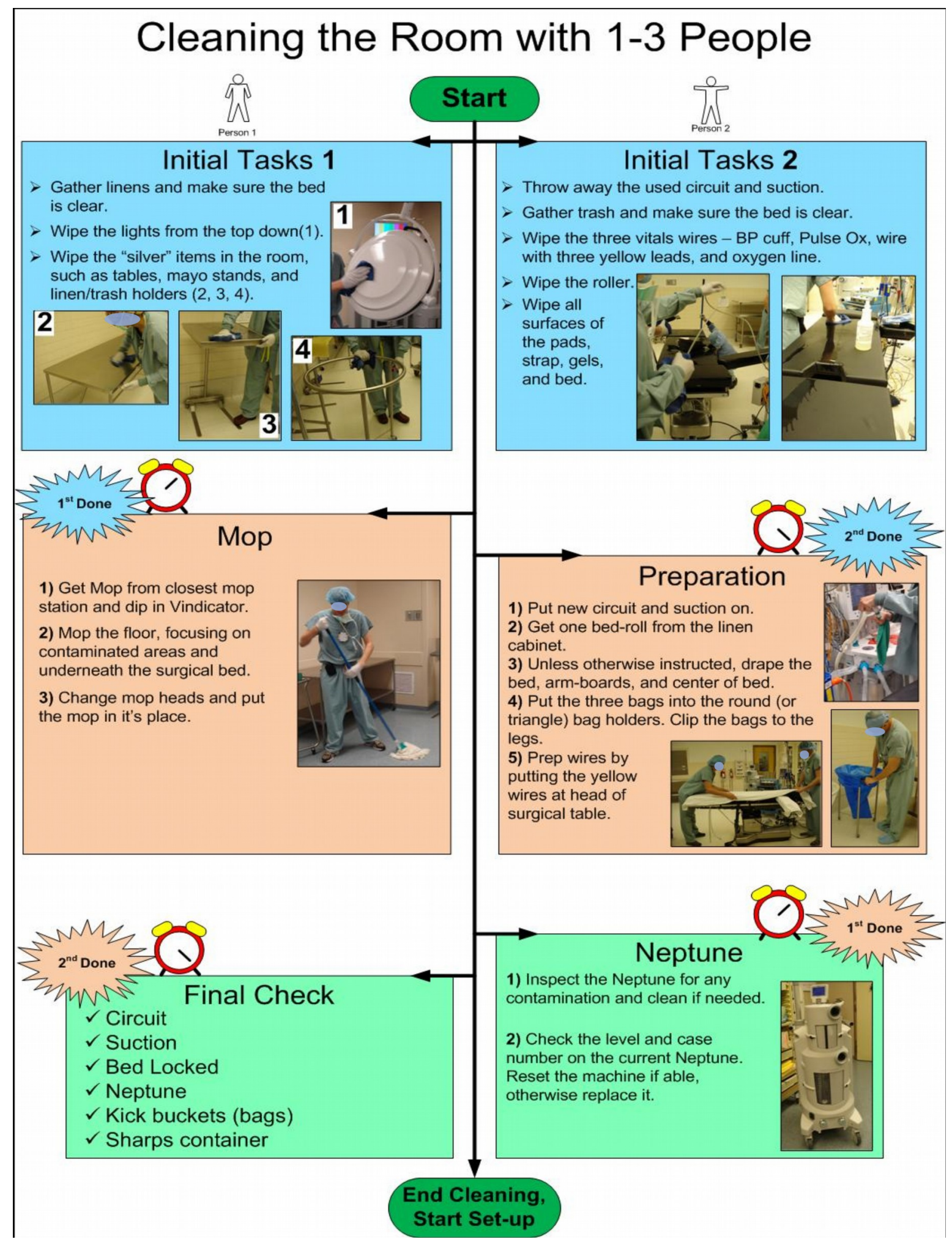

Figure 9. Concise ASWP

\subsection{Controlled Trial to Evaluate Detailed versus Concise Procedures}

The two pairs of aids who worked together most often were provided with the detailed written procedure. They performed it on a Monday and Tuesday of one week for all procedures, but data was collected for total hip and knee arthroplasty and revisions. For the rest of the week, Wednesday-Friday, the aides were allowed to clean the rooms as they had before. 
During the controlled trial, the aides were allowed to look at the cleaning ASWP as often as needed and were given the rule that only two aides (no more, no less) were allowed to clean the room at any given time. This rule was also told to the staff, which had mixed reactions. The two-aide rule was to help show that the room could still be cleaned quickly and efficiently with fewer people. Two days of experiments with over 15 turnovers were timed. The first five observations were not considered in the analysis, as aides were still going through the learning curve.

Two weeks later, on Monday and Tuesday, the same aides were shown the concise version of the procedure. As before, they were allowed to look at it as many times as needed. Once again, over 15 turnovers were timed, and the first five were not considered in the analysis.

Adherence was measured by using a checklist for each turnover in both the detailed and concise procedures. A Yes or No was assigned according to if they did a task or not. Each task for the individual aides was scored as a one or zero, respectively. If the other aide fulfilled the task, it did not count for the aide that was supposed to have completed the task. Both aides' scores were combined to create an overall score for each turnover.

The detailed ASWP adherence was 73\%, and the concise ASWP was 79\%. The difference was not statistically significant $(\mathrm{p}$-value $=0.110)$. The detailed ASWP took an average of 10.12 minutes, while the concise ASWP took an average of 10.42 minutes. The difference in average time was not statistically different either $(\mathrm{p}$-value $=0.197)$. However, the detailed ASSWP resulted in a standard deviation of 2.18 minutes, while the concise ASWP resulted in a standard deviation of 3.79 minutes; they were statistically different ( $\mathrm{p}$-value $<0.05$ ). The detailed ASWP was preferred since it resulted in a smaller standard deviation.

After the experiment, a meeting helped provide the research team feedback about the written procedures, even from those who had not participated. It was agreed that a simpler form of the procedure needed to exist, but the detailed ASWP would still be used for training new aides. The aides made suggestions about wording and what should go into the simplified version of the procedure.

\subsection{New (Future) State}

Once a final ASWP was agreed on, the aides performed the new procedure for about 12 new turnovers, and a future state VSM was created from the observations and time studies. Figure 10 shows the new state of the aides cleaning with the ASWP.

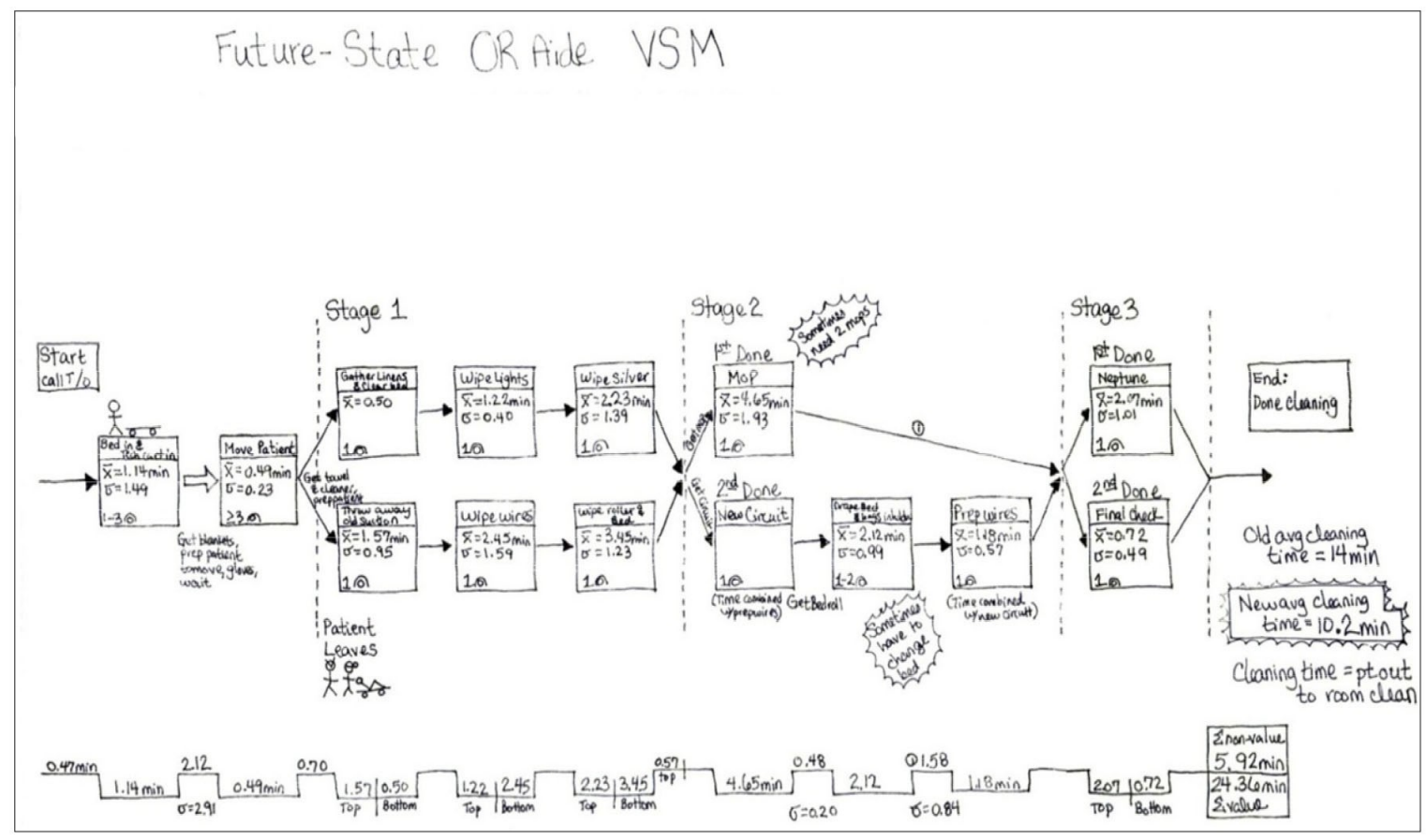

Figure 10. OR Aide Future (Implemented) State Value Stream Map 
The cycle starts when a turnover is called and ends when the room is clean. The times used for analysis are from the time the patient leaves until the room is clean. It can be seen that the process is much more linear and less chaotic. The value-added time decreased as tasks have been redistributed. The non-value-added time decreased as well. Therefore, the overall total time decreased along with the standard deviation due to the standardized work. According to the Future State VSM, the OR cleaning can be accomplished ideally on an average of 10.2 minutes.

Figure 11 presents the old versus the new turnover times, taken four weeks after implementing the ASWP. Turnover time for the ASWP was 11.80 minutes, which is 2.20 minutes faster than the old average but a little over a minute and a half more than the original time aides did during the observations captured in the Future State VSM (10.2 minutes). However, the current aides were new hires. They were still in training and still learning everything that goes on during a turnover, including the cleaning and bed configurations.

What is more important is the decrease in standard deviation; it decreased from 5.22 minutes to 1.93 minutes, which is substantial. This difference was statistically significant $(\mathrm{p}$-value $=0.001)$ and one of the most significant findings of creating an ASWP.

The new ASWP mandated that no more than three people may clean at any one time. Other staff members should do activities they are specifically trained for, such as the patient care aspect of a turnover and tasks they can only do.

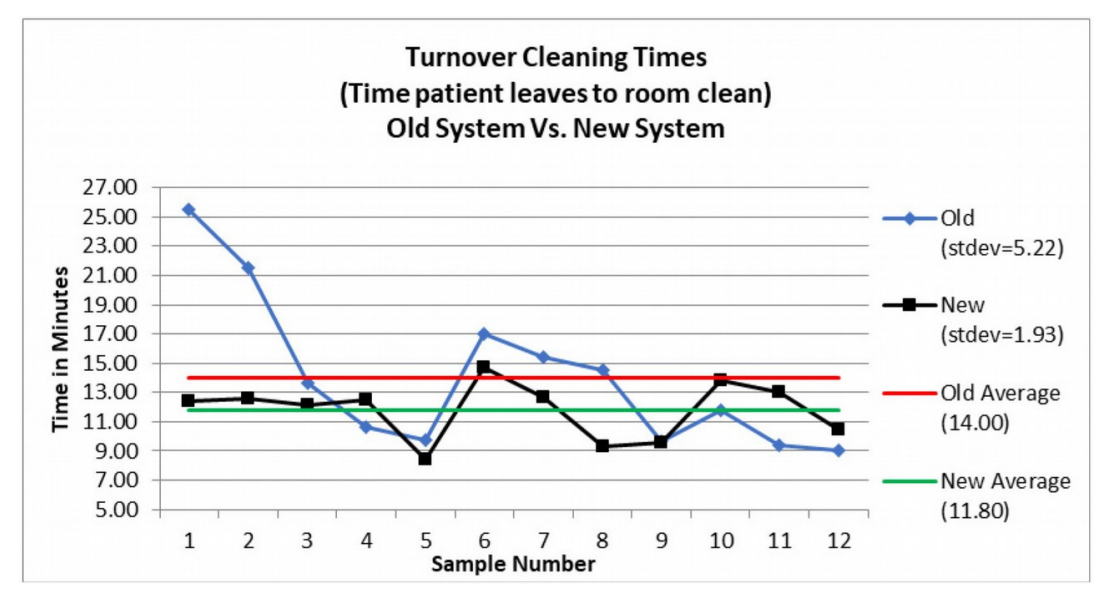

Figure 11. Turnover Cleaning Times Comparison

\section{Discussion}

This research focused on creating an agile standardized work procedure (ASWP) for cleaning the ORs after each surgery. The ASWP is considered agile because the same work is getting done every time, but since the number of people performing the work can vary, the work procedure can quickly and easily adjust to staffing changes. Anywhere from 1-3 people at any time can still complete the standardized work procedure.

The old cleaning method was highly dependent on how many people were available, and there were no assigned tasks. Nurses and aides shared with the research team that sometimes equipment in the room got cleaned multiple times (over-processing) or not at all, depending on the communication; and getting help in the room was hard because no one knew what was happening as far as the cleaning or set-up process. Therefore, the benefit of standardized work was allowing more communication with fewer people so that everything got cleaned the same way every time.

The research team spent some time shadowing and collecting data to understand the process. Findings were presented to the staff, which facilitated a discussion about the differences between what was observed and what was supposed to be happening or if a process was defined. It also allowed questioning if some of the actions were required, personal preferences, or "how it has always been done." 
A Kaizen Event was conducted where tasks were distributed by clustering them in groups according to precedence (serial tasks) and created parallel streams of those groups (parallel tasks) while preserving the required precedence between and within groups.

We designed a detailed and concise ASWPs and compared their performance according to completion time and adherence. The means of the detailed and concise written ASWP were found not to be statistically significant. However, the standard deviation was statistically different. This is contrary to what Randolph (2006) suggests, which is to have a simple language, consistent format, and easy to use procedures.

After the experiment, a simplified ASWP was created to be posted in every OR for a quick reference. This reminder poster can be seen in Figure 12. It is in the same format as the previously written procedures but only used keywords and showed how a third person, if available, would be able to help. ("Silver" was their term for all the metal fixtures in the room, such as the tables or stands).

Along with this reminder, the staff was informed that no more than three people cleaning were allowed so that communication would increase and allow others to do other tasks.

The ASWP successfully decreased the time and standard deviation of the cleaning part of the turnover. This helped with reducing the overall turnover variability. Figure 13 depicts the procedure shown as agile for 1, 2, or 3 people.

There can be different combinations of 1, 2, or 3, while the procedure is being performed. The procedure's adaptability also allows any combination of 1,2, or 3 people to come in and out of the cleaning process. For example, the turnover might start with one person and end with three people, or three people may start, and the cleaning ends with one because the others had to take care of other turnovers.

For example, when having two people available to do the cleaning, each of the two people will start with specific tasks. From the figure, it can be seen that there is a burst inside the Mop square that reads " 1 st Done". This indicates that the first done from their tasks grabs the mop, while the other will start prepping the room once they are done with their tasks. Whoever is done from the second round of tasks first will take care of resetting or changing the Neptune and putting kick bucket bags, while the person who finished second will be in charge of doing the final check.

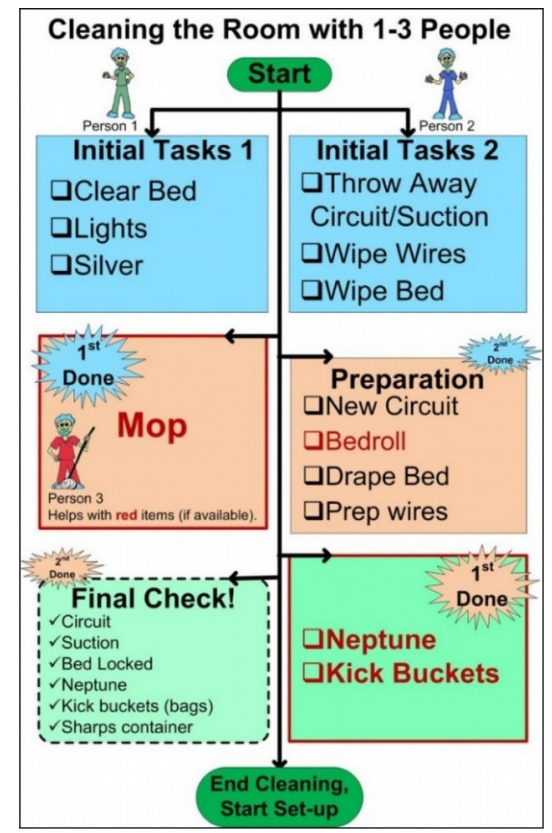

Figure 12. Cleaning Procedure Room Reminder 
If one person cleaning:

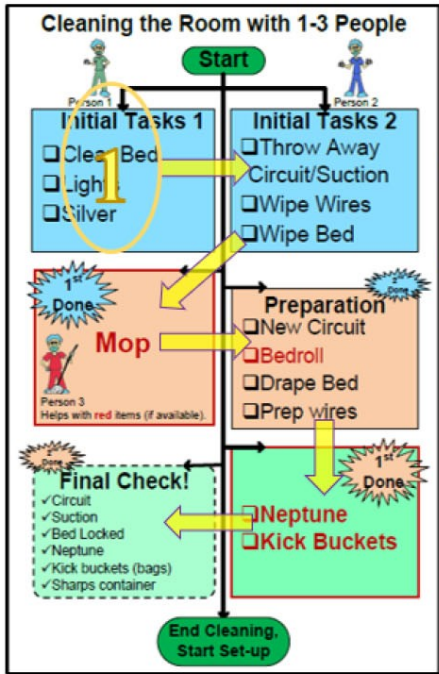

If two people cleaning:

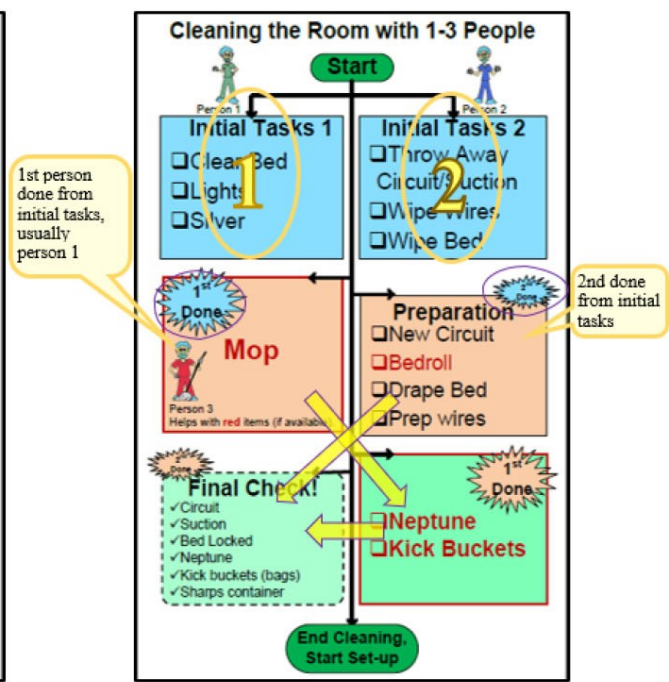

If three people cleaning:

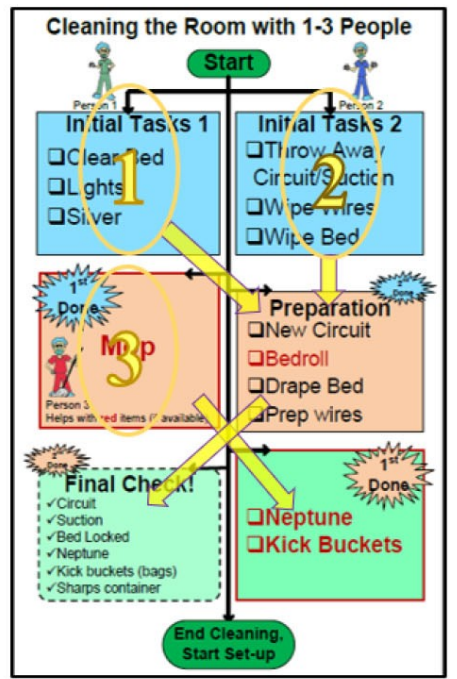

Figure 13. How the flexibility works on the in-room reminder

The ASWP was implemented for cleaning ORs after all types of surgeries. After 692 surgeries, the ASWP was proven to work for all types of surgery (not just certain types), which, according to Cima et al. (2011), is not currently documented in the literature. We were able to accomplish this with the creation and implementation of an ASWP. The overall turnover time (cleaning + preparing the room for the next surgery) for all surgeries was reduced by an average of 1.1 minutes, and the standard deviation was reduced by 1.8 minutes. Both resulted in statistical

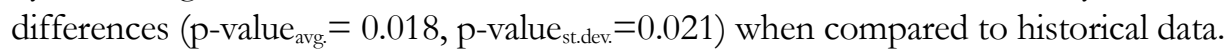

The times saved in the OR during non-operative time adds up, only if it is a minute or two for every turnover. Since it costs $\$ 33 /$ minute to run the ORs and they are not recouping the costs between surgeries, every minute counts. The hospital's savings with only two minutes reduced is about $\$ 13,200$ a month for an average of 50 turnovers a week and four weeks per month.

The collaboration between the research team and the owners of the process let aides and nurses know that their guidance and active participation made the difference in having impactful outcomes and reaching sustainability of the changes and improvements. Strategies such as empowerment, engagement, and leadership directly from the aides and nurses in discussion sections and, more importantly, in the decision-making process allowed the team to get into the implementation face and the project's success. The involvement of such stakeholders makes the difference between a success or a failure in the trajectory of a Lean or Kaizen project in the healthcare sector (Lindsay, Kumar \& Juleff, 2020; Nino, Claudio, Valladares \& Harris, 2020)

One phrase that can be heard about healthcare is that standardization and standardized work are hard to implement because "every patient is different." There is no way to predict what can happen or be able to make every process the same. Yes, there will be different equipment and different setups because each nurse or doctor likes their room in a particular way, and patient complications happen. However, not all tasks are surgery specific. Every room needs to be cleaned, linens on the bed need to be changed, contaminated supplies, instruments, and trash need to leave the room, and every room needs to be mopped. Understanding how to unlink the staff's prejudices from everyday work was important in getting creating the ASWP.

Involving aids in the improvement process and talking about the importance of following the ASWP was crucial to the reception of the new standards (Lindsay et al., 2020). Some aides were not completely following the steps, but talking about the new ASWP in the context of patient safety opened their eyes to the fact that following a 
procedure that did the same thing every time would help them create a safer environment for their patients. It wasn't just about money anymore, like they had heard their manager discuss multiple times; they were making a difference for their patients by following this new procedure.

After the implementation of the ASWP, the hospital noted a slight decrease in infection rates. We cannot claim that the ASWP directly improved the infection rates as multiple factors could influence a patient's outcome. However, we can at least say that the ASWP did not have a negative effect on the infection rates of patients.

\section{Conclusion}

This research looked at how an agile standardized work procedure (ASWP) for the turnover cleaning stage in the OR decreases the time and standard deviation and works across all types of surgeries' turnovers. ASWP refers to allowing the process to be completed the same way every time effectively with any number of people ranging from 1 to 3 . The flexibility not only accounts for the number of people who are to complete the procedure but also considers that some of them are only available during portions of the cleaning stage due to multiple turnovers or duties.

A standard deviation decrease was the first sign of the improvements affecting everyday activities and turnover times. This means that if the standard deviation of the entire turnover can be decreased, not just the cleaning, the schedule will become more accurate because turnovers are only scheduled for specific amounts of time, depending on the surgery. The cleaning ASWP is only one step, but if the entire turnover can become predictable, new turnover times for the schedule can be made to help scheduled surgeries occur on time.

This research work presents how an issue was resolved successfully for all types of surgeries at one hospital. Future research should focus on replicating an agile standardized work procedure in different contexts and comparing whether the results converge or diverge with those of this work.

\section{Declaration of Conflicting Interests}

The authors declared no potential conflicts of interest with respect to the research, authorship, and/or publication of this article.

\section{Funding}

The authors received no financial support for the research, authorship, and/or publication of this article.

\section{References}

Akmal, A., Greatbanks, R., \& Foote, J. (2020). Lean thinking in healthcare - Findings from a systematic literature network and bibliometric analysis. Health Policy, 124(6), 615-627. https://doi.org/10.1016/j.healthpol.2020.04.008

AORN (2012). 2012 Perioperative Standards and Recommended Practices: For Inpatient and Ambulatory Settings. AORN, Inc.

Bakken, S., Cimino, J.J., \& Hripcsak, G. (2004). Promoting Patient Safety and Enabling Evidence-Based Practice Through Informatics. Medical Care, 42(2), II-49-II-56. https://doi.org/10.1097/01.mlr.0000109125.00113.f4

Carroll, N., Bjørnson, F.O., Dingsøyr, T., Rolland, K.H., \& Conboy, K. (2020). Operationalizing agile methods: examining coherence in large-scale agile transformations. Paper presented at the International Conference on Agile Software Development. https://doi.org/10.1007/978-3-030-58858-8_8

Chkouri, M.Y. (2019). Integrate and Apply the Recommendation System of Agile Methods. Paper presented at the International Conference on Advanced Intelligent Systems for Sustainable Development.

Cima, R.R., Brown, M.J., Hebl, J.R., Moore, R., Rogers, J.C., Kollengode, A. et al. (2011). Use of Lean and Six Sigma Methodology to Improve Operating Room Efficiency in a High-Volume Tertiary-Care Academic Medical Center. Journal of the American College of Surgeons, 213(1), 83-92. https://doi.org/10.1016/j.jamcollsurg.2011.02.009

Dal Forno, A.J., Pereira, F.A., Forcellini, F.A., \& Kipper, L.M. (2014). Value Stream Mapping: a study about the problems and challenges found in the literature from the past 15 years about application of Lean tools. The International Journal of Advanced Manufacturing Technology, 72(5-8), 779-790. https://doi.org/10.1007/s00170-014-5712-z 
de Mast, J., Kemper, B., Does, R.J.M.M., Mandjes, M., \& van der Bijl, Y. (2011). Process improvement in healthcare: overall resource efficiency. Quality and Reliability Engineering International, 27(8), 1095-1106.

https://doi.org/10.1002/qre.1198

de Oliveira Rosa, T., \& Goldman, A. (2020). Is It Possible to Apply Agile Methods to Contribute to the Linux Kernel? Paper presented at the International Conference on Agile Software Development. https://doi.org/10.1007/978-3030-58858-8_30

Dingsøyr, T., Dybå, T., Gjertsen, M., Jacobsen, A.O., Mathisen, T.E., Nordfjord, J.O. et al. (2019). Key lessons from tailoring agile methods for large-scale software development. IT Professional, 21(1), 34-41. https://doi.org/10.1109/MITP.2018.2876984

Fireman, M.C., Saurin, T.A., \& Formoso, C.T. (2018). The role of slack in standardized work in construction: An exploratory study. Paper presented at the Proceedings of the 26th Annual Conference of the International Group for Lean Construction. https://doi.org/10.24928/2018/0213

Fogliatto, F.S., Anzanello, M.J., Tonetto, L.M., Schneider, D.S., \& Muller Magalhães, A.M. (2020). Lean-healthcare approach to reduce costs in a sterilization plant based on surgical tray rationalization. Production Planning \& Control, 31(6), 483-495. https://doi.org/10.1080/09537287.2019.1647366

Freivalds, A. (2009). Niebel's methods, standards, and work design. Boston, MA.: McGraw-Hill Higher Education.

Gladysz, B., Santarek, K., \& Lysiak, C. (2017). Dynamic spaghetti diagrams. A case study of pilot RTLS implementation. Paper presented at the International Conference on Intelligent Systems in Production Engineering and Maintenance. https://doi.org/10.1007/978-3-319-64465-3_24

Gonzalez-Aleu, F., Van Aken-Eileen, M., Cross, J., \& Glover-Wiljeana, J. (2018). Continuous improvement project within Kaizen: critical success factors in hospitals. The TQM Journal, 30(4), 335-355. https://doi.org/10.1108/TQM12-2017-0175

Graban, M. (2012). Lean hospitals: improving quality, patient safety, and employee engagement. CRC press.

Iivari, J., \& Iivari, N. (2011). The relationship between organizational culture and the deployment of agile methods. Information and Software Technology, 53(5), 509-520. https://doi.org/10.1016/j.infsof.2010.10.008

Ishikawa, K., \& Loftus, J. (1990). Introduction to quality control, 3 A Corporation. Tokyo, Japan.

Jabar, M.A., Ali, N.M., Jusoh, Y.Y., Abdullah, S., \& Mohanarajah, S. (2019). Adaptive and Dynamic Hybrid Model for Software Project Management: A Review on its Clarity and Usage to Improve Project Success. Paper presented at the Applied Mechanics and Materials. https://doi.org/10.4028/www.scientific.net/AMM.892.38

Koyle, M.A., AlQarni, N., Odeh, R., Butt, H., Alkahtani, M.M., Konstant, L. et al. (2018). Reduction and standardization of surgical instruments in pediatric inguinal hernia repair. Journal of Pediatric Urology, 14(1), 20-24. https://doi.org/10.1016/j.jpurol.2017.08.002

Krichbaum, B.D. (2008). Standardized Work: Creating Continuous Flow. Available at: www.processcoachinginc.com/Forms/Standardized\%20Work.ppt

Kumar, R., Singh, K., \& Jain Sanjiv, K. (2019a). Agile manufacturing: a literature review and Pareto analysis. International Journal of Quality \& Reliability Management, 37(2), 207-222. https://doi.org/10.1108/IJQRM-12-2018-0349

Kumar, R., Singh, K., \& Jain Sanjiv, K. (2019b). Development of a framework for agile manufacturing. World Journal of Science, Technology and Sustainable Development, 16(4), 161-169. https://doi.org/10.1108/WJSTSD-05-2019-0022

Lehmann, C.U., \& Miller, M.R. (2004). Standardization and the Practice of Medicine. Journal of Perinatology, 24(3), 135-136. https://doi.org/10.1038/sj.jp.7211060

Lindsay, C.F., Kumar, M., \& Juleff, L. (2020). Operationalising lean in healthcare: the impact of professionalism. Production Planning \& Control, 31(8), 629-643. https://doi.org/10.1080/09537287.2019.1668577

Lokhande, S.P., \& Sarode, A.D. (2020). Identification \& Prioritization of Agile Manufacturing Enablers for Small and Medium Scale Industries. IOP Conference Series: Materials Science and Engineering (810, 012034).

https://doi.org/10.1088/1757-899X/810/1/012034 
Marchwinski, C., \& Shook, J. (2008). Lean lexicon: a graphical glossary for lean thinkers (4th ed.). Lean Enterprise Institute.

Marin-Garcia, J.A., Juarez-Tarraga, A., \& Santandreu-Mascarell, C. (2018). Kaizen philosophy: The keys of the permanent suggestion systems analyzed from the workers' perspective. The TQM Journal, 30(4), 296-320. https://doi.org/10.1108/TQM-12-2017-0176

Nino, V., Claudio, D., Valladares, L., \& Harris, S. (2020). An Enhanced Kaizen Event in a Sterile Processing Department of a Rural Hospital: A Case Study. International Journal of Environmental Research and Public Health, 17(23), 8748. https://doi.org/10.3390/ijerph17238748

Olivieri, H., Seppänen, O., Alves, T.d.C., Scala, N.M., Schiavone, V., Liu, M. et al. (2019). Survey Comparing Critical Path Method, Last Planner System, and Location-Based Techniques. Journal of Construction Engineering and Management, 145(12), 04019077. https://doi.org/10.1061/(ASCE)CO.1943-7862.0001644

Pérez, B., \& Porres, I. (2010). Authoring and verification of clinical guidelines: A model driven approach. Journal of Biomedical Informatics, 43(4), 520-536. https:// doi.org/10.1016/j.jbi.2010.02.009

Poth, A., \& Wolf, F. (2017). Agile procedures of an automotive OEM-views from different business areas. Paper presented at the European Conference on Software Process Improvement. https://doi.org/10.1007/978-3-319-64218-5_42

Randolph, S. (2006). Developing Policies and Procedures. AAOHN Journal, 54(11), 501-504. Available at: https://search.proquest.com/docview/219334086?pq-origsite $=$ gscholar\&fromopenview $=$ true https://doi.org/10.1177/216507990605401104

Reichert, M., Dadam, P., \& Bauer, T. (2004). Dealing with forward and backward jumps in workflow management systems. Informatik Forschung und Entwicklung, 18(3-4), 132-151. https://doi.org/10.1007/s00450-004-0157-5

Rother, M., \& Shook, J. (1999). Learning to See. Brookline, MA: Lean Enterprise Institute. Inc..

Senderska, K., Mares, A., \& Vaclav, Š. (2017). Spaghetti Diagram Application For Workers'movement Analysis. UPB Scientific Bulletin, Series D: Mechanical Engineering, 79(1), 139-150.

Simpson, K.R. (2009). Standardization. MCN: The American Journal of Maternal/Child Nursing, 34(1), 72. https://doi.org/10.1097/01.NMC.0000343877.56097.e3

Sommer, A.F. (2019). Agile Transformation at LEGO Group: Implementing Agile methods in multiple departments changed not only processes but also employees' behavior and mindset. Research-Technology Management, 62(5), 20-29. https://doi.org/10.1080/08956308.2019.1638486

Vest, J.R., Gamm, L.D., Oxford, B.A., Gonzalez, M.I., \& Slawson, K.M. (2010). Determinants of preventable readmissions in the United States: a systematic review. Implementation Science, 5(1), 88. https://doi.org/10.1186/17485908-5-88

Worley, J.M., \& Doolen, T.L. (2011). Turnovers and Turnarounds in the Healthcare System. In Yih, Y. (Ed.), Handbook of healthcare delivery systems (1st ed.). Boca Raton: CRC Press.

Zareei, S. (2018). Project scheduling for constructing biogas plant using critical. Renewable and Sustainable Energy Reviews, 81(1), 756-759. https://doi.org/10.1016/j.rser.2017.08.025

Journal of Industrial Engineering and Management, 2021 (www.jiem.org)

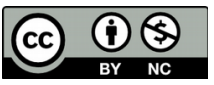

Article's contents are provided on an Attribution-Non Commercial 4.0 Creative commons International License. Readers are allowed to copy, distribute and communicate article's contents, provided the author's and Journal of Industrial Engineering and Management's names are included. It must not be used for commercial purposes. To see the complete license contents, please visit https://creativecommons.org/licenses/by-nc/4.0/. 